\title{
La Modernidad, cuestión de estilos. Simmel y la necesaria insuficiencia de la concepción estética de la vida ${ }^{1}$
}

\author{
José Gaspar Birlanga Trigueros \\ Universidad Autónoma de Madrid \\ josegaspar.birlanga@uam.es / birlanga@gmail.com
}

Analizar y abrazar la vida, pensarla e intuirla simmelianamente nos permitirá abordar la cuestión de los distintos modos y estilos de vida, y muy en particular del estético, pero sobre todo propiciará tomar conciencia de la vida: de ser y de hacernos vida. Hacemos nuestro también el punto de partida y planteamiento que Simmel mantenía en su Intuición de la vida: también nosotros hacemos un ensayo para comprender la vida como tal. Y ello es especialmente relevante en los tiempos modernos en los que lo planteaba Simmel.

En éstos, el suelo nutricio de la tragedia de la cultura, existencia y vivencia moderna es precisamente el conflicto permanente entre vida y forma, entre alma y mente, entre el flujo continuo de la individualidad y la tendencia a la estandarización, que caracteriza a la cultura moderna. Esta

1 Cabe aclarar que este artículo se encuentra también publicado, por el mismo autor, en: Grupo de Investigación Filosófica USB-USAL, III Simposio Internacional: Concepciones de lo real y estilos de vida (Salamanca, 7-10 abril). En: investigacionfilosofica.usal.es/Eventos.html. 
irreconciliable oposición entre individuo y sociedad, entre subjetividad y objetividad, creaba, y crea aún hoy, un malestar cultural difuso y penetrante ${ }^{2}$. Pero en esa misma situación advertimos también, con Simmel, algo que se manifiesta cada vez con mayor insistencia: el deseo del individuo por alcanzar una zona segura, más allá de la zozobra y la fragmentariedad de la existencia cotidiana, para escapar a la complejidad de la vida y a la zozobra constante. Busca, en definitiva, un ámbito en donde sea posible una concepción unitaria de la vida. Adelantamos ya que para mucha gente, dice Simmel, <ese anhelo cobra carácter estético〉, y así, parecería poder encontrar, en esa concepción artística, la ansiada liberación respecto la fragmentariedad y la angustia de la vida real ${ }^{3}$.

La vida se expresa palmariamente para Simmel en un proceso, ininterrumpido y creador: no puede ser contenida en formas u objetos. El acabamiento y la estaticidad es más bien un reclamo para abandonar y destruir los diques de la vida; para rebasar, cualquier forma que se presente como definitiva pero sólo para cristalizarse otra vez en nuevas formas. Ésta es la antinomia básica de la vida: que se convierte, no tanto en una patología, cuanto en la tragedia misma de la cultura, cuando separa el ámbito subjetivo del objetivo, indicando que en este proceso y entre aquellos límites que marca

2 Cuesta no reconocer la 〈similitud - -deuda- de los postmodernos para con Simmel. Éste ya indicó, como dan cuenta sus textos, cómo lo social y lo cultural son ámbitos inseparables, aunque es necesario reconocer que parte de los últimos debates sobre la postmodernidad parten del reconocimiento de la modernidad como un fenómeno sociocultural. Ciertamente que no fue sólo Simmel, también, entre otros, Marx, Weber o Durkheim, mostraron las conexiones no ya sólo entre lo cultural y lo social.

3 En el fondo, el fin supremo del 〈art pour l'art〉 consistía precisamente en aquella representación de la totalidad de forma y vida mediante un itinerario exclusivamente estético, aunque como veremos la postura de Simmel es bien distinta y no sólo en el fondo. 
la propia vida, hay mucho en juego respecto al individuo y su destino. El individuo produce distintos y muy variados objetos culturales, con distintos fines a los de mantener su vida y desarrollar sus potencialidades. Así, no sólo debe emplear la totalidad de los productos humanos que pertenecen al ámbito del espíritu/cultura objetivo/a, sino que, además, ha de intentar al menos interiorizarlos y reintegrarlos en la corriente de su vida. Así pues, una vida que:

[...] rebasa constantemente los límites que la separan de su más allá, teniendo su propia esencia en este rebasamiento; el ensayo de hallar en este trascender la definición de la vida, y, aún ateniéndonos a lo cerrado de su forma de individualidad, lo hacemos solamente considerando que ésta es quebrantada en un proceso continuo (Simmel, 1950: 32).

Reintegración y rebasamiento sin cesar. Los elementos del espíritu objetivo, como formas acabadas, disociadas del torrente vital, alcanzan entonces su propia dinámica. Se hacen autónomos y se desarrollan de acuerdo con su lógica interior, ya no como medios, sino como fines en sí mismos. De tal suerte que se produce una inversión en el proceso, que bien pudiera expresarse diciendo que si al principio el hombre quiere conocer para vivir, después algunos hombres viven sólo para acumular, en el mejor de los casos, más conocimientos, cuando no se conformen simplemente con objetos. De ahí que términos como 〈inquietud〉, 〈desencanto〉y 〈ansiedad que se traducen en el de «malestar〉 sean aquellos que marcan magistralmente, y no sólo por Simmel, a la cultura y existencia modernas. La consecuencia es clara: el hombre es dominado y esclavizado por sus propios productos; es decir, El conflicto de la cultura moderna. Conflicto, patología y trage- 
dia, que hunde sus raíces en la condición misma de la vida y en su tensión con las formas, en las que aquélla, inevitable y necesariamente, se expresa. Hacernos cargo, desde una concepción de la vida, de semejante conflicto entre vida y forma en su tragedia se presenta como la conditio sine qua non para asumir y lograr el nuevo estilo de vida moderno, para constituirnos.

Se trata, por tanto, de producirnos, de constituirnos en protagonistas de nuestra vida, a través de la continua superación de las formas de esta vida con otras formas de existencia, cada vez más alejadas de la mera experiencia y más cercanas a la intimidad de la vivencia. Y, para ello, nos queda sólo el superarnos a nosotros mismos, asumiendo nuestras limitaciones y contradicciones. Pero para ello se impone la necesidad de un estilo de vida que pueda permitir semejante empresa: reinsertarnos de nuevo en el vértigo de la vida, en su frenético devenir, para comenzar nuevamente a transitar vitalmente cultura subjetiva y objetiva, vida y forma, pues «solo al hombre le es dado, frente a la naturaleza, el ligar y el desatar, y ciertamente en la sorprendente forma de que lo uno es siempre la presuposición de lo otro» (Simmel, 1986: 29).

\section{II}

La vida personal de Simmel fue también reflejo de su concepción filosófica al respecto ${ }^{4}$. Querer ser más vida, aspirar

4 Aunque para abundar, sobre esta cuestión, remitimos especialmente a los trabajos de David Frisby y Esteban Vernik, y a la revisión contemporánea del Simmel «sociólogo〉 que coordinó Olga Sabido Ramos, publicada por Anthropos-UAM-Azcapotzalco en el 2007. Conviene tener mínimamente presente que la consolidación académica en la vida docente universitaria no fue fácil para Simmel. De hecho sólo le llegó al final de su vida y además en 
a ser más-que-vida: así podría resumirse su concepción de la vida: «La vida halla su esencia, su proceso, en ser precisamente más-vida y más-que-vida, su positivo como tal es ya su comparativo que en este punto se llegue al estrato en que las circunstancias lógicas imponen irremisiblemente silencio, porque es aquel de donde se nutre la raíz metafísica de la lógica misma» (Simmel, 1950: 32).

No lo fue menos su vida intelectual en la que destacó más como alentador que como sistemático, más como intérprete de la modernidad que como académico de la misma. A Simmel le delata desde luego su estilo: la evocación, la sugerencia, pero no más que sus fuentes. Entre ellas, desde luego, como él mismo reconoce ya en los mismos títulos de dos de sus libros, Kant y Goethe, 1906; y Schopenhauer y Nietzsche, 1907. Frente al idealismo y a la epistemología positivista, y en tanto que antecedente de la fenomenología, como Adorno lo reconoce, Simmel se autoexigía llegar a las cosas mismas -que ecos en nuestro Ortega-, pero ya no desde el espíritu de la estaticidad-objetividad de antaño. Por eso también su pensamiento y hacer filosófico es centrífugo: será desde esa vida desde dónde se analizará, en todo su dinamismo, la modernidad, sacando a la luz la totalidad de las direcciones de la vida moderna, fragmentarias y centrífugas. Por contrapartida, y muy

una Universidad no deseada por él, muy lejos de su siempre añorada vida berlinesa. Fue en la Universidad de Estrasburgo, y cuatro años antes de su muerte, donde logrará la cátedra de Filosofía. La vida se le fue, y ello a pesar del reiterado e incondicional apoyo de los hermanos Weber, de Troeltsch y del reconocimiento académico que le concedía E. Husserl, H. Rickert, H. Vaihinger, pero también personalidades culturales como H. Keyserling, Stefan George, incluso Lou-Andreas Salomé, esa descubridora de talentos, y desde luego por los miembros de su privatissimo, como solía llamarse a los amigos que se reunían en el salón de su casa, R. M. Rilke, S. George, A. Rodin, Paul Ernst, Gundolf entre otros, además de algún que otro alumno próximo, como Bloch y Lukács, que no reconocieron, como debieran, la influencia de su maestro. 
coherentemente, no puede lograrse el principio concéntrico, la idea central, pues, como Simmel recuerda, vivimos en una época sin Rey, sin mayúsculas, sin idea central, sin estilo incluso que contenga el rebasamiento continuado de la vida: el sujeto necesita ajustarse continuamente al devenir vital -iperspectivismo orteguiano?- y ello implica serle necesariamente, en algún momento, infiel al estilo que uno adopta: «en un sentido tanto inmediato como simbólico, tanto corporal como espiritual, somos a cada instante aquellos que separan lo ligado o ligan lo separado» (Simmel, 1986: 29).

La importancia concedida a la vida, desde luego también junto a otros elementos que, como veremos, concurren en esa consideración, fue determinante para que Simmel no se postulara como sociólogo a pesar del éxito que supuso su Sociología (1986c). La moderna vida individual se vive ineludiblemente con otros, es, pues, también social. Por eso Simmel estudia las formas de socialización, es decir, los modos que adoptamos para ser la vida personal en sociedad. Pues bien, esas mismas formas de socialización se desarrollan conforme a otras mayores y menores, y más o menos intuitivas, pero siempre más personales e igualmente eficaces para reconocernos, y para ser reconocidos, en nuestras formas menores de vivir la vida que constituye lo que ha venido en llamarse los estilos de vida. No ha de extrañarnos, pues, que la insuficiencia manifiesta de una Sociología-sin-vida aparezca criticada de múltiples maneras en la obra de nuestro autor.

Resulta reveladora la crítica que ha recibido su Sociología. Ha sido calificada como a-sistemática pero rica, brillante aunque no sistemática; algunos dicen que carece de valor por su recurrente dispersión, aunque no pueden dejar de reconocer la brillantez de sus sugerentes ideas; hay quienes la critican por su incapacidad para hablar de la sociedad como 
de un todo coherente, sin embargo, reconocen que se detuvo muy fecundamente en aspectos de lo social verdaderamente inusitados. Otros, en fin, que aunque intuitiva e impresionista, su Sociología descuidaba la sistematización de los materiales... En este breve repaso de algunas de las caracterizaciones realizadas falta, a nuestro entender, la de ‘coherente), pues propone una sociología en donde la concepción de lo vital pesa mucho más que la de lo social. $\mathrm{O}$, dicho de otra manera, donde los estilos o formas de vida priman sobre los estilos o formas de socialización, que quedan subordinadas a aquellos. Por ello, coherentemente, Simmel ofreció una configuración absolutamente nueva de las ideas sociales, sustituyendo el estilo y los temas academicistas por el ensayo y la atención al carácter fragmentario de la vida moderna, que requiere seguir siendo pensada como filosofía de la cultura, del arte, desde la reflexión estética, pero sobre todo como filosofía de la vida.

Es indudable que los resultados producidos por la actividad estética, intelectual, práctica o religiosa, forman esferas particulares, regidas cada cual por sus leyes; cada uno de ellos produce en su lenguaje, a su manera, el mundo o un mundo; pero esta autonomía de nuestros distintos mundos solo se refiere a su contenido cuando se lo considera con independencia de su producción. Y solo en cuanto que este contenido se piensa en abstracción separado y se escinde de las energías reales de la vida espiritual, solo así considerado puede parecer que todas aquellas corrientes de la vida corren unas al lado de las otras sin comunicación (Simmel, 2005: 85).

No podía ser de otra forma, pues para Simmel todo ello emerge de una concepción y filosofía de la vida que, frente a la infertilidad de la objetividad, entiende que su principio no puede ser otro que la autotranscendencia: «Lo uno o lo 
otro: aceptas el principio de la Selbsttranszendenz [autotranscendencia] o lo rechazas. Si lo aceptas, no puedes ya, no debes ya detenerte: serás simmeliano y vitalista hasta el final» (Jankélévitch, 2007: 22).

Así pues, qué y quién mejor que el ensayo sobre El problema del estilo (1908) y Georg Simmel para comenzar a mostrar la necesidad de un estilo de vida, también en relación con el arte y la estética, que pueda hacer frente a la oposición constante entre lo individual y lo colectivo, entre la cultura objetiva y la subjetiva, que atraviesa y constituye la modernidad. Quién mejor que el amplio registro cultural que Georg Simmel ofrece: sociólogo, filósofo de la cultura y de la vida, de la economía y del dinero, esteta y filósofo del arte, pedagogo y antropólogo. Qué mejor que el variado campo de pruebas de sus escritos para valorar la riqueza de su filosofía de la vida: metafísica, estética, arte, música ${ }^{5}$, psicología, sociología, historia, epistemología, moral, religión, economía, filosofía de la cultura. En definitiva, Simmel propone toda una filosofía de la vida afín a los tiempos modernos, una filosofía de la vida que la haga visible hasta en los elementos más insospechados (el asa, los Alpes, la coquetería, la moda, el viaje). La concepción de la vida en Simmel es toda una convocatoria a virar con/hacia la vida, entendida en las formas (sic) más dinámicas y versátiles en las que pueda ser pensada. De esta manera, como se defenderá, el viraje hacia la vida es ya el modo de ser moderno: estar pendiente de ella, vivirla a flor de piel. El estilo de vida moderno asume como imperativo vivir la vida como vida, sin otra categoría que la subsuma, aligere o esconda: subjetividad, conciencia -individual o de

5 Para abundar sobre el modo en que la música incide y se relaciona con la concepción, en este caso, simmeliana de la vida puede consultarse (Birlanga, 2013). 
clase-, pero también, espíritu o naturaleza, sociedad o Estado, ninguna de ellas puede o debe aligerar la concepción de la vida moderna.

Pero, ¿qué cabe entender por vida para Simmel y desde este contexto de modernidad? La influencia de Nietzsche en este punto también es incuestionable:

El concepto de vida en Nietzsche muestra una reunión semejante de los fenómenos interiores en un fin común, al que están subordinados todos los fines individuales. En él, la vida se destaca como un valor absoluto, que es lo absolutamente significado en las manifestaciones diversas de la existencia. El querer -y lo mismo el conocer y el sentir- no es más que un medio de intensificación de la vida; ésta comprende en su concepto irreductible a todas nuestras funciones particulares. Es interesante notar que, así como en Nietzsche el proceso de la vida se apodera de la voluntad como de su órgano y medio, en Schopenhauer, por el contario, la voluntad adquiere aquel significado absoluto según el cual la vida misma no es más que una de sus manifestaciones, un medio de expresarse a sí mismo y de hallar su camino (Simmel, 2005: 86).

Desde luego no es una vida ni plena ni máximamente biológica, pues la vida requiere de una conciencia que la viva; de hecho, en alemán se delimita muy bien al distinguir erleben de leben. El animal vive, pero no vive su vida, el hombre, además de vivir, vira del vivir para vivir su vida. En Simmel, ese vivir su vida apela al viraje: a vivir la vida desde una concepción no biologicista, pero tampoco espiritualista, aunque sin preterir a ninguna de ellas. Veámoslo. Puede decirse que para vivir es necesario que leben y erleben se muevan para no quedar fijados. Desde el punto de vista de la experiencia estética, como 
veremos, esa actitud vital sugiere, y Simmel es un epígono de ello, una apelación a cambiar el punto de referencia, desde la experiencia [Erfhärung] hasta la vivencia [Erlebnis]; desde el ver hacia el mirar, del arte a la estética, augurando ya la estetización del mundo que se avecinaba.

La naturaleza humana, y muy especialmente en la modernidad, solo puede ser entendida en relación con ese autorrebasamiento de sí [Sich-Selbst-Ueberschtreiten], en esa autotranscendencia. Así, la vida tiene continuamente que superarse a sí misma tanto en la dirección biológico-vital de ser más-vida [Mehr-Leben], la dirección de la experiencia, como en la dirección más subjetiva y cultural, más propiamente humana, como más-que-vida [Merh-Als-Leben], la dirección de las vivencias. Aunque Simmel reconoce la contradicción lógica que ello supone -quien se sobrepasa a sí mismo, es el que sobrepasa pero, al mismo tiempo, lo que se sobrepasa- entiende que en el devenir vital de la modernidad las dualidades, las dicotomías dejan de ser insalvables pues: el yo es derrotado venciendo y vence derrotando. Era necesario cambiar la concepción de la vida para llegar a comprender y asumir la profunda tragedia que residía en el hecho de que para que la vida pueda existir, deba convertirse, primero y recurrentemente, en no-Vida. Que la cultura subjetiva solo puede edificarse de nuevo sobre la objetiva, o, en relación a El problema del estilo, que el hecho de que las personas tiendan a generar un estilo en su vida y hogares en un punto equidistante entre la unicidad de un solo estilo y un estilo individual y único, es una analogía que utiliza Simmel para, yendo más allá, plantear tanto el papel del sujeto en la sociedad, cuanto para sondear la relación de autonomía del primero respecto a la segunda. Ciertamente: 
Desde hace mucho tiempo se ha dicho que la existencia práctica del hombre se desenvuelve en la lucha ente la individualidad y lo colectivo, es decir, que en casi cada momento de nuestra existencia la obediencia a una ley que sea válida para todos -sea de naturaleza interna o externa- entra en conflicto con la determinación interior pura de nuestra existencia, con la individualidad personal que sólo obedece a su propio sentido de vida (Simmel, 1988: 319).

La vida viva necesita de aquel autorebasamiento; y él explicaría tanto como fundamentaría la necesidad de un estilo desde y con el que afrontar y dar forma a la vida, conteniéndola, hasta su inevitable rebasamiento. De ahí también la necesidad del estilo y de la infidelidad a él. Ser fiel a un estilo no sería sino una restauración del canon, del clasicismo, de la quietud y del reino del estatismo del ser y la sustancia, y ello es indeclinable en las condiciones en los que devienen los tiempo nuevos. Este proceder es sin duda trágico porque necesitamos de un estilo/forma de vida, pero ser fiel a esta última, requeriría renunciar a un solo estilo, se es infiel al estilo que quiere postularse como único, o excluyente, porque la vida no puede contenerse y menos en una única, inmutable, parmenídea, forma/ estilo de vida. Necesitamos del estilo de vida, pero necesitamos que este estilo sea superado, desbordado por la vida.

Lo que empuja con fuerza al hombre moderno hacia el estilo es la exoneración y el revestimiento de lo personal, que es en lo que consiste la naturaleza del estilo. El subjetivismo y la individualidad se han agudizado hasta llegar al punto de quebrarse, y en las formas estilizadas, desde las del comportamiento hasta las de la decoración de la vivienda, se produce una suavización y un atemperamiento de esa personalidad aguda hacia lo general 
y su legalidad. Parece como si el yo ya no pudiera sostenerse a sí mismo o al menos ya no se quisiera mostrar, por lo que se envuelve en un atuendo general, más típico, en una palabra, estilizado (Simmel, 1988: 325).

III

En su Intuición de la vida Simmel se refiere al hombre como el ser que menos seguro está de su teleología. Pues bien, esta inseguridad sería otro motivo para «serle infiel〉 al estilo, incluso serle constitutivamente infiel. Ello, por contrapartida, permite al individuo el mayor radio de acción, fijar sus límites con la mayor independencia del automatismo vital de su cuerpo (de su más vida). Le permite, en fin, la condición vital para el rebasamiento (más que vida).

Ahora bien ¿es posible un ámbito en donde ese finalismo sea burlado?, ¿puede el arte ofrecer un estilo de vida afín a la concepción moderna de la vida?, ¿cabe, en definitiva, algún tipo de experiencia que permita quebrar la concatenación teleologizante de la existencia?, ¿cabe concebir cómo vivir la vida y no sólo vivirla?, ¿cabe un estilo de vida que, como ocurre con los estilos artísticos, con-forme a la vida de manera que nos alivie de esa necesaria infidelidad continuada? «La significación interna de los estilos artísticos se puede interpretar como una consecuencia de la distancia distinta que establecen entre nosotros y las cosas. Todo arte transforma la perspectiva en la que, originaria y naturalmente, nos situamos frente a la realidad» (Simmel, 1977: 597). ¿Cabe, en fin, algún estilo en el que quepa cierto descanso y quietud sin que deje de haber vida?

La vida del hombre moderno, del metropolitano, se ve invadida por objetos 〈de diseño〉. La profusión consumista de los mismos sin que ninguno de ellos agote su necesidad, 
indicaría, en negativo, una búsqueda que no cesa. El urbanita así alcanza finalmente lo contrario de lo que se proponía, un aprisionamiento en las cosas. Por eso Simmel ve en las corrientes vivas del arte, los movimientos de vanguardia artística a los que asiste en esos días:

[...] la búsqueda de estilos nuevos, del estilo en general, el simbolismo, incluso la teosofía, son síntomas de una necesidad nueva de dar a las cosas un significado más profundo, ya porque cada una obtiene una significación más valiosa y más espiritual, ya porque obtenga esta significación de la creación de una conexión, o a través de la liberación de su atomización (Simmel, 1977: 504).

Efectivamente, también aquí, cabe hablar de esa reestructuración de sentido que lleva a cabo el sujeto en sus creaciones, resta por saber ahora si será capaz de aplicar la misma configuración significativa a su vida y al mundo en el que la vive. Y desde luego que en este punto el ámbito estético continúa gozando, en palabras de Simmel, de un encanto impresionante.

La totalidad del todo se encuentra en lucha perpetua contra la totalidad del individuo La imagen estética de esto es especialmente impresionante porque el encanto de la belleza se vincula siempre a una totalidad, ya tenga una viabilidad inmediata por sí misma, ya a través de la fantasía, como sucede con lo fragmentario. El sentido del arte consiste en configurar una totalidad autónoma, un microcosmos que no precisa nada del mundo exterior a partir de un fragmento casual de la realidad, que, por razón de su falta de autonomía, se encuentra unido con ésta por mil hilos. El conflicto típico entre el individuo y el ser supraindividual se puede representar como el impulso 
irreconciliable en ambos por alcanzar una imagen estéticamente satisfactoria (Simmel, 1977: 626).

El resultado obtenido, como consecuencia de esa retirada hacia nosotros mismos sería, escribe Simmel, «una relación más íntima y auténtica con las cosas» (Simmel, 1977: 599); y aunque ello pudiera ser efectivamente realizable, nos toparíamos con la siguiente realidad que nuestra alma, con sus efímeros impulsos, con su fragmentario poder, no puede configurar ninguno de estos mundos hasta la totalidad que exige idealmente. Por todo ello, no es posible el ideal perseguido desde el ámbito estético, allí donde se producen las

[...] actividades vitales más profundas. Pero precisamente el hecho de que estas imágenes del mundo carezcan de la autosuficiente redondez de su contenido objetivo produce actividades vitales más profundas y conexiones anímicas, pues cada una de ellas impele a lo siguiente, a crear a partir de la otra, impulsos, contenidos, tareas, que en una elaboración interna sin lagunas encontraría en sí misma (Simmel, 1986: 173).

Simmel asiste a la vorágine de la sucesión de vanguardias históricas, distintos estilos y programas que tenían como uno de sus principales objetivos el devolver el arte a la vida, y acabar así con la duplicidad de mundos estructurados en función de, enunciado de un modo simmeliano, una cultura subjetiva y otra objetiva. Ello puede leerse como síntoma de la insatisfacción del propio arte a la hora de lograr esa imagen global de la existencia. Lo mismo acontece si realizamos una visión más microscópica del fenómeno estético al aplicarlo a la estetización general de la vida que sufre el urbanita, y en la que también hoy estamos inmersos. De ahí la urgencia del estilo de vida. 
En el anhelo por superar la zozobrante existencia moderna, pero no por ello sin dejar al tiempo de ser, o propiamente subsistir, en la satisfacción de la existencia empírica Simmel siguiendo a Schopenhauer sugiere al respecto una concepción de la vida, y salida, de marcado sesgo estético:

Schopenhauer enseña que el intelecto tiene de cuando en cuando la posibilidad de liberarse de la esclavitud de la voluntad; pero entendiendo aquí por intelecto [...] la esfera de conciencia en que se forma el cuadro intuitivo del mundo en general. [...] En estos momentos de absoluta contemplación estamos de tal modo saturados de la imagen de la cosa, que desaparece la condición de la voluntad y la causa del tormento que nos proporciona el sentir que el yo y su objeto se oponen, que están separados por un abismo insondable de carácter espacial y temporal (Simmel, 2005: 86-87).

La experiencia estética, pues, puede procurarnos un estilo con el que parece posible una liberación del finalismo. La obra de arte para Simmel se caracteriza por su carácter cerrado, aislado y por su unidad objetiva, por su autosuficiencia [Selbstenügsamkeit] y su aislamiento [Fürsichsein]:

De esta suerte se encuentran en una total contradicción con la obra de arte, la cual está soberanamente encerrada en sí misma, cada una constituye un mundo propio, un objeto de sí misma, simbolizando con ese marco, que rechaza cualquier participación al servicio de los movimientos de una vida práctica, que se encuentra fuera de ella (Simmel, 1988: 322).

La experiencia estética, en una sociedad excitada y neurasténica, cumple también la función de moderar, purgar, los des- 
equilibrios. Permite un modo o estilo de vida adecuado. La obra de arte acapara privilegiadamente esta función, siquiera tan sólo, por lo siguiente: son los vehículos con los que se transmiten, forman y legitiman las normas morales que rigen el devenir vital del individuo y de la sociedad a la que pertenece. Su extensión no debiera sorprendernos:

El principio de la tranquilidad, que debe estar en la base del entorno doméstico del hombre nos ha conducido con una precisión práctica maravillosa hacia una estilización de ese entorno: de todos los objetos de uso, los muebles son sin duda los que muestran de forma más consecuente ese carácter de un "estilo" definido (Simmel, 1988: 324).

Esta necesidad de recuperar fuerzas para la vida es todavía más necesario en las grandes ciudades. La vida espiritual, también y especialmente la metropolitana, requiere de ese aventurarse. Pues solo así la vida podrá soportar, asumir y superar (efímeramente) no ya el movimiento sino la febrilidad, no solo la inquietud sino la modernidad, tan angustiante como vibrante.

La obra de arte, que cuelga de la pared en un marco o que descansa en su pedestal o que se encuentra sobre el escritorio, muestra con esta delimitación espacial, que -al contrario de la mesa y del vaso, la lámpara y la alfombra- no participa en la vida inme diata, que no puede prestar a la personalidad el servicio de «una cosa secundaria necesaria» (Simmel, 1988: 324).

Por eso el arte delata al moderno, el arte con su forma cerrada enfatiza la rotundidad del aislamiento [Fürsichsein]. Por eso también esa objetividad aplastante requiere de la trans-forma- 
ción de un sujeto: que el sujeto en su aventura se trans-figure para salir al encuentro de la obra de arte que pueda detener por un instante la vida.

El estilo de vida moderno afecta a nuestra vida y a la consideración de los objetos. Así puede entenderse que, a medida en que nos alejamos de la obra de arte, se vaya desvaneciendo su relación con nosotros y la obra queda cerrada de nuevo como objeto, a la espera de que otro aventurero la salve de nuevo de la rotundidad de la objetualidad. El estilo de vida moderno también ha puesto de manifiesto esto: que el marco de relaciones ha dejado de ser unilateral [einseitig], ahora las relaciones son recíprocas [Wechselwirkung]. Sólo así cabe entender la experiencia estética como aventura.

El arte delata al moderno también en otro sentido: manifiesta la prioridad que éste concede al arte sobre la ciencia y la filosofía academicistas, porque, ante la obra, la vida es más-que-vida, y deja de ser sólo vida, acontece entonces ese 〈más〉 que permite la disolución del tiempo, del espacio, del sí mismo, de la objetividad, para acceder a una forma de experiencia que aunque efímera es privilegiada.

El arte no deja de ser -y tal vez no deba dejar de serlo- una invitación a concebir la vida de otra manera, como aventura, pues para que haya experiencia estética es necesario que el hombre rebase los límites de su individualidad aventurándose a la raíz de la vida, o por decirlo con Schopenhauer, a ser «puro ojo del mundo».

Tal es el sentido del arte, tanto para el que lo crea como para el que lo disfruta, que nos eleva más allá de nuestras propias circunstancias y de las del mundo dependiendo su valor de si hemos superado tales circunstancias, que actuarán como algo que ya no existe. $\mathrm{Y}$ cuando decimos que el encanto en el que vive la 
obra de arte no es más que la reminiscencia de aquél sentimiento autóctono, de aquella excitación originaria del alma, reconocemos que lo específico de la obra de arte no radica en aquello que es común a la forma inmediata y a la estética del contenido sentimental, sino el nuevo matiz que contiene a la última una vez que se ha disipado la primera (Simmel, 1977: 154-155).

\section{IV}

Parecería posible que la estética consiguiera dotar de sentido la existencia, que ella pudiera satisfacer la necesidad de sentido global del hombre. Sin embargo, no sucede así en el caso de Simmel: la estética es una forma de expresión perteneciente a la cultura objetiva y, como tal, está sometida a ese proceso de extrañamiento cada vez mayor del individuo para con ellas ${ }^{6}$. Todas las aspiraciones que el individuo pretenda realizar a partir de ellas acabarán siendo fagocitadas objetivamente, o, lo que es lo mismo, una vez fuera de nuestro sentimiento, ya no son el vehículo de expresión de nuestro sentido vital, ya nos son extrañas, ya no nos reconocemos en ellas. Aquella posesión que, gracias al distanciamiento propiciado por el arte y la religión, habíamos conseguido traer al alma deja de ser sumamente intima y autoevidente. Si la obra sólo fuese una copia de la realidad, entonces, dice Simmel: «el interés se transformaría repentinamente en indiferencia, porque en este caso la obra de arte ya no se diferenciaría de la realidad y perdería la justificación de su existencia» (Sim-

6 En Cultura, religión y religiosidad en Georg Simmel (Birlanga, 1996) se estudia si es posible asumir y soportar la tragedia de la cultura moderna adentrándose en el ámbito íntimo para reconocer si la religiosidad puede ser la salvaguardia del individuo y su libertad, si desde ella, en fin, puede el individuo satisfacer definitivamente sus anhelos de sentido. 
mel, 1977: 172-173). Éste es uno de los motivos fundamentales que llevan a Simmel a criticar el realismo artístico: por «la abolición de la distancia que media entre nosotros y la realidad; porque olvida que también él ordena y transforma la inmediatez de la impresión merced a determinados presupuestos y exigencias», y además afirma:

Este principio vital de todo arte, es decir, aproximarnos de tal manera a las cosas que nos colocamos a cierta distancia de ellas, reza también -muy a su pesar, añadimos nosotros- para el arte naturalista, cuyo sentido exclusivo parecería ser la abolición de la distancia que media entre nosotros y la realidad; puesto que tan sólo un autoengaño podría hacer olvidar al naturalismo que también él es un estilo, es decir, que también él ordena y transforma la inmediatez de la impresión merced a determinados presupuestos y exigencias, lo que se demuestra de modo irrefutable por medio de la evolución artística histórica, en el sentido de que, lo que una época consideraba la imagen verdadera y exacta de la realidad, una posterior lo trataba como un conjunto de prejuicios y falsificaciones, siendo ella la que iba a representar las cosas como son en verdad. El realismo artístico comete la misma falta que el realismo científico cuando cree que puede pasarse sin un (a priori), sin una forma que, nacida de nuestras disposiciones y necesidades, puede dar una nueva y distinta a la realidad sensorial (Simmel, 1977: 597-598).

Ello no supone, sin embargo, la negación de esa función liberadora que el arte tiene respecto a la contingencia de la existencia; nos libera, sí, pero no definitivamente. Alcanzar el sentido de la existencia así nos obligaría a extender ese proceso liberatorio al infinito, a partir de todos y cada uno de los aspectos de la realidad. Ello subraya aún más la nece- 
sidad de no olvidar que estamos transidos esencial y constitutivamente por la finitud; lo cual lo hace simplemente imposible. O como dice Simmel: «todas aquellas realidades conservan una última y profunda extranjería frente a nosotros; e incluso entre nuestra alma y la de los otros, nuestro deseo de dar y de recibir encuentra una desesperante insuperabilidad» (Simmel, 1986: 164).

Pero Simmel reitera que este itinerario estético sólo nos conduce a un escape de la realidad; que, en la medida en que se desarrolla en, desde, $y$, hacia la temporalidad, en ningún caso puede ser definitivo. Al estar constituido desde la esfera de la cultura objetiva, pues cualquier creación subjetiva pasa a ser considerada casi inmediatamente en la esfera objetiva, difícilmente, pues podrá la estética dotar de sentido unitario a nuestra existencia. Esa imposibilidad no es óbice, sin embargo, para que Simmel continúe manteniendo como objeto del análisis del presente a los fenómenos cotidianos, los aspectos que encontramos en nuestra experiencia diaria tanto individual como social; en fin, la capacidad «para experimentar el fenómeno individual, con todos sus detalles, la plenitud de su realidad. Para ese fin [...] es necesaria cierta retirada respecto del fenómeno para recuperar desde un punto de vista más elevado, su realidad más plena y profundamente» (Simmel, 1977: 179).

Así pues, si bien desde la estética no se puede alcanzar ese sentido global, sí al menos, y en tanto que nos permite liberarnos de la esclavitud de lo inmediato, podemos recurrir a ella como un apoyo más para que, liberándonos de lo inmanente, podamos alcanzar lo transcendente; tornando lo inhabitable en el lugar de la «vivienda vivencial», en fin, de eliminar, escribe Simmel, la frialdad ajena del mundo exterior. Todavía hoy la reflexión sobre el carácter liberatorio, además 
de libertario que tiene la experiencia, sigue siendo objeto incuestionable.

La liberación mediante la experiencia estética puede cumplirse sobre tres planos: la conciencia en cuanto actividad productora crea un mundo que es su obra propia; la conciencia en cuanto actividad receptora capta la posibilidad de renovar su percepción del mundo; finalmente -y aquí la experiencia subjetiva desemboca sobre la experiencia intersubjetiva- la reflexión estética adhiere a un juicio exigido por la obra, o se identifica con la norma de acción que ella esboza y que toca a sus destinatarios proseguir la definición (Jauss, 1978: 130).

Pero Simmel vuelve a sus fuentes y reconoce en el sábado de la voluntad de Schopenhauer, el anhelado descanso de la misma cuando se encuentra ante la obra de arte. La voluntad se repliega sobre sí ante ella, y deja ya de fatigarse en la satisfacción de sus necesidades porque ha encontrado aquello que satisface sus anhelos, o que los lleva al plano de lo secundario y preterible. Nuestra vida, ante la obra de arte, siente ya satisfechas sus necesidades; así, por fin, la voluntad descansa. La obra al ser aurática, no sólo está también cerrada; más bien da un portazo tras de sí al mundo, y se queda a solas con el yo, que deja de ser voluntad en tanto que entra en contacto con la obra bella, cerrada sobre sí y cerrada ante el mundo. Síntesis y antítesis al mismo tiempo: «Cuanto más profunda y única es la impresión que nos causa la obra de arte, menos suele ocuparnos la pregunta acerca de la cuestión del estilo de la obra» (Simmel, 1988: 319).

Pero este bálsamo es transitorio, la vida no se detiene más allá de lo que dura el sagaz engaño estético y se reactiva más volitivamente si cabe a la busca desesperada de una 
nueva puerta que cerrar tras de sí, al encuentro de una nueva obra de arte que oficie la transmutación.

Por ello, para Simmel cualquier experiencia estética es una invitación para ser infieles al estilo, tránsfugas de las formas de vida que ya no nos satisfacen a la hora de vivir la vida. La obra de arte, pues, lo delata. Ese carácter autónomo, cerrado, de la obra es signado por Simmel como 〈centrípeto〉. Si la obra es centrípeta, el hombre debe ser pues centrífugo para llegar a ella, debe vivir. La obra de arte es en este sentido y como dice Simmel en otro de sus ensayos una propuesta de vida, un aventurarse en ella, una aventura. La realidad insular del arte está a la espera, sin mezclarse con los objetos de la utilidad, medios para la satisfacción del yo en tanto que voluntad siempre insatisfecha hasta que alcanza la obra de arte. De ahí que Simmel distinga entre las bellas artes y las artes útiles, aunque en ambas hay siempre un rastro para la aventura.

Pero inexorablemente llega un momento en el que hay que parar, en que nuestra voluntad y nuestro espíritu exigen reposo. Pero Simmel niega esa quietud. La fuga estética nunca será definitiva.

Y desde el punto de vista de la estética, cabe añadir además que, si bien el arte es una forma de acercamiento a la realidad, captando así la relación inmediata con su sentido propio y más intimo y, tras la frialdad ajena del mundo exterior, nos deja atisbar la viveza del ser, a través de la cual éste nos resulta próximo y comprensible, por otro lado, otro aspecto característico de él, y fundamental para nuestra intención, es reconocer, al mismo tiempo, que «todo arte implica un alejamiento de la inmediatez de las cosas, hace que se reduzca su carácter concreto de los atractivos e interpone una especie de velo entre éste y nosotros» (Simmel, 1977: 587). 
Insistimos, esa aventura sólo puede ser una aventura: el arte y lo bello cautivan, si bien sólo temporal, efímeramente. Por ello la concepción de la vida debe ser modificada en la dirección de la aventura, es decir, se ha de virar continuamente para permanecer en esa actitud de estar-en-fuga de la determinación / condicionamiento de la existencia, burlando el finalismo. En el arte, la vida, como configuración siempre limitada que constantemente rebasa su limitación, aparca momentáneamente ese adverbio. La experiencia estética nos libera de la vida, de la satisfacción de sus necesidades, nos libera para hacer-nos más-que-vida. El estilo de vida estético nos des-embaraza, al menos por un momento del apremio continuado de la vida. Efectivamente se trata, aunque efímeramente, de un desinterés, como decía Kant, de una finalidad sin fin. (En otro lugar me atrevía a continuar escribiendo: «todo un kitKant (sic)» (Birlanga, 2009: 45).

Así, la contemplación de la belleza nos emancipa de la sola vida y, en esa medida, celebramos «el sábado de la voluntad», pues también llena nuestro espíritu desde un fragmento de la realidad. De esta manera, la experiencia estética es para el artista, como para el recién llegado hombre moderno, un acceso a lo esencial de lo dado más allá de cualquier relación teleológica: los contenidos están allí, en lo eterno del arte, ajenos a los juicios que regulan las relaciones entre los hombres y las cosas, en el mundo de la representación objetiva; es decir, libres de cualquier determinación. Así pues, Simmel postula con su viraje una doctrina valiente y seductora, que acrisola, no sin complejidad, distintas influencias y que se encuentra presente en El problema del estilo, y de la vida, pues:

Finalmente, el estilo es el intento estético de solucionar el gran problema de la vida: cómo una obra única o un comportamiento 
único, que constituye una totalidad, cerrada en sí misma, puede pertenecer al mismo tiempo a una totalidad superior, a un contexto unificador más amplio (Simmel, 1988: 326).

En conclusión, no sólo en el fondo de la tragedia de la cultura moderna reside nuestra concepción de la vida. El estilo en que ésta se vive, es decir, la concepción moderna de la vida pasa por la comprensión de la que la negación de la vida es inherente a la misma. Por eso no podía ser solo más vida. Paradójicamente, la vida en su flujo, en su devenir continuado, genera en sí misma las formas que la asfixiarán y ello de manera inevitable, de ahí la tragedia: la muerte es inmanente a la vida. Parece pues que vivir modernamente no puede ser sino vivir trágicamente, es decir, sin síntesis final: más-vida y más-que-vida, escapando de la alternativa dogmática movilidad o reposo. Vivir modernamente es dejar que la vida viva, es decir, vérselas en un cuerpo a cuerpo con aquello que niega la vida y en lo que sin embargo se reencuentra viviendo -el estilo, entre otros-, en vías de una nueva negación.

Bibliografía

Birlanga, J.G. (2013). G. Simmel: la búsqueda de una tierra no pisada. Scherzo. Revista de Música. Año XXVIII - No 287, 76-80. Birlanga, J.G. (2009). G. Simmel: transfuguismo como rebasamiento. El kit-kat de la experiencia estética. Despalabro: Ensayos de humanidades, 3, 41-45.

Birlanga, J.G. (1996). Cultura, religión y religiosidad en G. Simmel. Religión y cultura. Vol. XLII - No 196, 55-86. Jankélévitch, V. (2007). Georg Simmel, filósofo de la vida, A. García Castro (trad.). Barcelona: Gedisa. 
Jauss, H. R. (1978). Pour une esthétique de la réceptio. París: Gallimard.

Simmel, G. (2005). Schopenhauer y Nietzsche, F. Ayala (trad.). Buenos Aires: Prometeo Libros.

Simmel, G. (1988). El problema del estilo. Revista Española de Investigaciones Sociológicas 84, 319-326.

Simmel, G. (1986a). Puente y puerta. En Salvador Mas (trad.). El individuo y la libertad. Ensayos de crítica de la cultura. Barcelona: Península.

Simmel, G. (1986b). El cristianismo y el arte. En Salvador Mas (trad.). El individuo y la libertad. Ensayos de crítica de la cultura. Barcelona: Península.

Simmel, G. (1986c). Sociología. Estudios sobre las formas de socialización, J. R. Pérez Bances (trad.). Madrid: Alianza Editorial.

Simmel, G. (1977). Filosofía del dinero. R. García Cotarelo (trad.). Madrid: Instituto de Estudios Políticos.

Simmel, G. (1950). Intuición de la vida: Cuatro capitulos de metafísica. J. Rovira (trad.). Buenos Aires: Nova. 


\section{Resumen}

La pluralidad de estilos y la deslealtad del hombre hacia ellos son para G. Simmel característico de la Modernidad y del desmoronamiento de las mayúsculas clásicas que guiaron nuestra existencia. Los estilos de vida también se impregnan de esta moderna época sin rey, trágica para la cultura y el individuo. La concepción estética de la vida, y el intento del arte de burlar la impersonal teleología, pudiera ser la alternativa, pues la experiencia estética nos libera del encadenamiento a la vida objetivada, a la satisfacción de sus necesidades; nos des-embaraza del apremio de la vida, pero solo efímeramente: se revela así tan necesaria como insuficiente.

Palabras clave: modernidad, estética, vida, estilo, Simmel.

\section{Abstract}

According to G. Simmel, the diversity of styles and mankind's disloyalty towards them are representative of Modernity and the collapse of classic capital letters that have guided our existence. Lifestyle is also pervaded by this modern kingless era, a tragic era for culture and individuals. The aesthetic conception of life and art's attempt to outwit the impersonal theology could be the alternative, since the aesthetic experience releases us from this shackle of objectivized life, of the fulfillment of its necessities; it rids us of life's urgency, but only ephemerally: it reveals itself as necessary as insufficient.

Key words: modernity, aesthetic, life, style, Simmel. 